\title{
Enfermería Clínica
}

\section{Factors associated with suicidal ideation among older people in medical outpatient clinic ${ }^{\text {th }}$}

\author{
Sharifah Munirah Syed Elias ${ }^{a}$, Aniawanis Makhtar ${ }^{\mathrm{a}, *}$, Nor Hazwani Ahmad Tarmidi ${ }^{\mathrm{b}}$ \\ a Department of Special Care Nursing, Kulliyyah of Nursing, International Islamic University Malaysia, Kuantan, Pahang, Malaysia \\ ${ }^{\mathrm{b}}$ Kulliyyah of Nursing, International Islamic University Malaysia, Kuantan, Pahang, Malaysia
}

Received 15 September 2020; accepted 21 September 2020

\section{KEYWORDS \\ Older people; \\ Suicidal ideation; \\ Outpatient clinic}

\begin{abstract}
This study aimed to determine the prevalence of suicidal ideation and the associated factors with suicidal ideation among older people. This was a cross-sectional study. The present study was carried out from March 2018 to May 2018. In total, 200 older people aged 60 years and over were recruited from a medical outpatient clinic in Malaysia. The older people completed a self-administered questionnaire on sociodemographic background, depression, and suicidal ideation. The data analysis involved descriptive and inferential analysis using IBM SPSS Statistics version 23.0. The prevalence rate of suicidal ideation was $3 \%$. There were significant associations between ethnicity $(p<0.00)$, marital status $(p=0.008)$, depression $(p<0.00)$ and suicidal ideation. Risk factors for suicidal ideation in older people are ethnicity, marital status, and depression. Future studies should focus on these factors in any intervention aimed to reduce suicidal ideation among older people in Malaysia.

(c) 2020 Elsevier España, S.L.U. All rights reserved.
\end{abstract}

\section{Introduction}

With the increasing numbers of older people worldwide, it is anticipated that mental health problems will also increase.

\footnotetext{
Peer-review under responsibility of the scientific committee of the 4th International Conference for Global Health (ICGH) in conjunction with the 7th Asian International Conference in Humanized Health Care (AIC-HHC). Full-text and the content of it is under responsibility of authors of the article.

* Corresponding author.

E-mail address: aniawanis@iium.edu.my (A. Makhtar).
}

One of the significant impacts of mental health problems among older people is suicidal ideation. ${ }^{1}$ Suicidal ideation is defined as a thought of killing oneself that mistaken as normal feelings due to the aging process and reduced physical abilities. ${ }^{1,2}$ It is a complex phenomenon involving physical, psychological, and social factors present at a critical period in the life of older people. ${ }^{2}$ Because the occurrence of suicidal ideation is significant along with potent predictors of suicide attempts and completed suicide, ${ }^{2,3}$ it is vital to explore the risk factors related to suicidal ideation among older people.

Generally, the prevalence rates of suicidal ideation in older people worldwide ranged from $5 \%$ to $47.8 \%$. In South 
Korea, it was found that $10.9 \%$ of older people aged 65 -yearold and older reported suicidal ideation. ${ }^{4}$ Similarly, 4.1\% of older people in a study among older Chinese Americans aged 60 years and older reported suicide ideation. ${ }^{5}$ Other research revealed that $5.1 \%$ of older people in China and $14 \%$ of older people in the United States of America (USA) reported suicidal ideation. ${ }^{6,7}$ Among the Malaysian population, it was found that $47.8 \%$ of older people who have committed suicide were reported having suicidal ideation. ${ }^{2}$

The association between sociodemographic factors and suicidal ideation among older people was found to be inconsistent in previous studies. Some research reported the significant association of age with suicidal ideation with 75-years or older greatly affected by suicidal ideation. ${ }^{6,8,9}$ On the contrary, another study found that the younger age group (65-69 years old) is prone to have suicidal ideation compared to those in the oldest-old age group (80 years and older). ${ }^{4}$ Moreover, there is a conflicting result of the relationship between gender and suicidal ideation. Although previous research stated the absence of gender and suicidal ideation association, ${ }^{6,7}$ a more recent study found that gender was correlated with suicidal ideation, with females being more prone to have suicidal ideation. ${ }^{10}$ Meanwhile, studies regarding marital status testified a significant association between marital status and suicidal ideation in older people. ${ }^{11,12}$ Further, it was reported that being widowed was associated with higher levels of suicidal ideation. ${ }^{12}$ Interestingly, despite limited study focusing on the association between ethnicity and suicidal ideation among older people, the Chinese are the most common ethnic (80\%) that have committed suicide compared to the Malays and Indian. ${ }^{2}$

It is well established that depression is strongly linked to suicidal ideation. Many studies found that depression is correlated with suicidal ideation, ${ }^{7-9,13,14}$ where a higher level of depression was positively related to suicidal ideation. ${ }^{4}$ Furthermore, depression had the strongest predictors of suicidal ideation. ${ }^{15}$ Generally, most of the previous studies involved older people living in the community with limited studies involved in other settings, such as outpatient clinics. ${ }^{8}$

Despite extensive research investigating risk factors for suicidal ideation among older people, the data obtained from medical outpatient clinics are scarce. Similarly, in Malaysia, the study regarding suicidal ideation involving older people are also limited, as previous studies are more focused on adults and young adults. ${ }^{2}$ Therefore, this study aimed to determine the prevalence rate of suicidal ideation and its association with other factors such as sociodemographic characteristics and depression among older people in Malaysia.

\section{Method}

This was a cross-sectional study conducted from March 2018 to May 2018. In total, 200 older people aged 60 years and over who attended a medical outpatient clinic in Peninsular Malaysia were involved in this study. The sampling method used in the present study was convenience sampling. The inclusion criteria for participants were those aged 60 years and over, beside could understand and speak Malay or English. Meanwhile, the exclusion criteria comprised of having severe or chronic mental illness such as schizophrenia and bipolar disorders and the inability to obtain informed consent. Firstly, the researcher approached the potential participant in the waiting area in the medical outpatient clinic. A brief explanation of the purpose and significance of the study was given to the participants who met the inclusion criteria

If the participants were willing to take part in the study, they were asked to fill out the consent form. After receiving informed consent, the questionnaires were circulated and retrieved after completion.

\section{Measures}

The questionnaire used in the present study could be divided into three parts; (1) Part A: Sociodemographic background, (2) Part B: Depression by Geriatric Depression Scale (GDS15), ${ }^{16}$ and Part C: Suicidal ideation by Suicide Behaviors Questionnaire-Revised (SBQ-R). ${ }^{17}$ For part A, data related to age, gender, ethnicity, and marital status were collected from the participants. For part B (GDS-15), a total of 15 questions were asked to the participants, in which they have to respond by answering yes or no on how they felt over the past week. The questionnaire was a close-ended questionnaire where the score is given based on the bolded answer. Scores 0-4 were considered normal, 5-8 were categorized as mild depression, 9-11 indicate moderate depression, and 12-15 indicate severe depression. The GDS-15 reported $92 \%$ sensitivity and $89 \%$ specificity when evaluated against diagnostic criteria. Part C (SBQ-R) was comprised of four questions. The total participant's score was obtained from all the questions. Scores 0-3 indicate that the participants have no suicidal ideation, while scores 4-13 indicate participants have suicidal ideation in their life. A pilot test was conducted among 30 older people to pre-test the questionnaire related to GDS15 and SBQ-R. Good internal consistency (Cronbach's alpha of 0.7) was obtained for both GDS-15 and SBQ-R.

\section{Ethical considerations}

This study obtained ethical clearance from the ethical committees of the IIUM Research and Ethics Committee (IREC) and the Medical Research and Ethics Committee (MREC). The ethical clearance from the IREC and MREC included the medical outpatient clinic where data collection occurred.

\section{Data analysis}

Statistical software (IBM SPSS Statistics version 23.0) was used for data analysis. The data were analyzed as a descriptive and inferential analysis. Fisher's Exact Test was used for inferential analysis. $p$-Value $<0.05$ was set as statistically significant.

\section{Results}

\section{Sociodemographic background}

Table 1 shows the sociodemographic background of the participants in this study. The majority of the participants were 
Table 1 Sociodemographic characteristics.

\begin{tabular}{lrl}
\hline & $\begin{array}{c}\text { Frequency } \\
(n=200)\end{array}$ & $\begin{array}{l}\text { Percentage } \\
(\%)\end{array}$ \\
Age & & \\
$60-65$ & 129 & 64.5 \\
$65-70$ & 43 & 21.5 \\
$70-75$ & 28 & 14.0 \\
Gender & & \\
Male & 91 & 45.5 \\
Female & 109 & 54.5 \\
Ethnicity & & \\
Malay & 181 & 90.5 \\
Chinese & 16 & 8.0 \\
Indian & 3 & 1.5 \\
Marital status & & \\
Married & 185 & 92.5 \\
Single/divorce & 12 & 6.0 \\
Widowed & 3 & 1.5 \\
\hline
\end{tabular}

female, which account for about $54.5 \%$ of the participants. The majority of the participants were Malay (90.5\%). The participants were divided into three groups according to their age, with the majority of participants in the age group of $60-65$-year-old $(64.5 \%)$. About $92.5 \%$ of the participants were married.

\section{The prevalence rate of suicidal ideation among older people}

The present study found that $3.0 \%$ of the participants reported suicidal ideation with the mean suicidal ideation of $3.10(S D=0.56)$.

\section{Association between sociodemographic characteristics and suicidal ideation}

Table 2 demonstrates the results of the association between sociodemographic factors and suicidal ideation. Significant associations between ethnicity $(p=0.000)$ and marital status $(p=0.008)$ with suicidal ideation were observed from the analysis. However, no significant association was detected between age and suicidal ideation $(p=0.305)$. Similarly, no significant association was recorded between gender and suicidal ideation $(p=0.691)$.

\section{Association between depression and suicidal ideation}

Table 3 shows the significant association between depression and suicidal ideation $(p=0.000)$.

\section{Discussion}

The present study found that the prevalence rate of suicidal ideation among older people was $3.0 \%$. To the best of our knowledge, this study is the first study in Malaysia that reported the prevalence of suicidal ideation among
Table 2 Association between sociodemographic data and suicidal ideation.

\begin{tabular}{|c|c|c|c|c|}
\hline & \multicolumn{2}{|c|}{ Suicidal ideation } & \multirow[t]{2}{*}{$x^{2}$} & \multirow[t]{2}{*}{$p$-Value } \\
\hline & No & Yes & & \\
\hline Age & & & 2.093 & 0.305 \\
\hline $60-65$ & 126 & 3 & & \\
\hline $65-70$ & 42 & 1 & & \\
\hline $70-75$ & 26 & 2 & & \\
\hline Gender & & & 0.369 & 0.691 \\
\hline Male & 89 & 2 & & \\
\hline Female & 105 & 4 & & \\
\hline Ethnicity & & & 22.736 & $0.000^{*}$ \\
\hline Malay & 180 & 1 & & \\
\hline Chinese & 11 & 5 & & \\
\hline Indian & 3 & 0 & & \\
\hline Marital status & & & 11.669 & $0.008^{*}$ \\
\hline Married & 182 & 3 & & \\
\hline Single/divorce & 9 & 3 & & \\
\hline Widowed & 3 & 0 & & \\
\hline
\end{tabular}

Table 3 Association between depression and suicidal ideation.

\begin{tabular}{llllll}
\hline & \multicolumn{2}{c}{ Suicidal ideation } & & $X^{2}$ & $p$-Value \\
\cline { 2 - 3 } & No & Yes & & \\
\hline Depression & & & 27.506 & $0.000^{*}$ \\
$\quad$ Normal & 141 & 0 & & \\
Mild & 32 & 0 & & \\
Moderate & 9 & 0 & & \\
Severe & 12 & 6 & & \\
\hline Note & & & & \\
$*$ p-Value $<0.05$. & & & \\
\end{tabular}

older people. In contrast, the previous study reported a prevalence rate of suicidal ideation among older people in Malaysia involving suicide victims. ${ }^{2}$ The prevalence rate was relatively lower than the previous studies. Previous research found that the prevalence rates of suicidal ideation ranged from $5 \%$ to $47.8 \% .^{4-7}$ The low prevalence rate of suicidal ideation in Malaysia may be attributed to the fact that suicide is considered a taboo culturally and religiously among the Malaysian population. ${ }^{18}$

For sociodemographic factors, ethnicity and marital status were found to be significantly correlated with suicidal ideation among older people. It was reported that $90.5 \%$ of the participants were Malays. In comparison to the previous study, it was found that the Chinese contributed to $80 \%$ of suicide death. ${ }^{2}$ It could be postulated that although the Malays tend to have suicidal thoughts, the thoughts may not contribute to suicide attempts.

The present study found a significant association between marital status and suicidal ideation. The finding was following the findings obtained in previous studies that reported marital status is related to suicidal ideation.9,10 In the 
present study, $92.5 \%$ of the participants were married. This finding was congruent with the previous study that reported the majority of the suicide victims with suicidal ideation were married. ${ }^{2}$ It could be implied that despite being married, older people might be suffering from an unhappy marriage. It was supported by a study that found unhappy marriage is linked to suicidal ideation. ${ }^{12,19}$ Conversely, a previous study documented that marital status was not associated with suicidal ideation. ${ }^{8}$ Therefore, further work is required to establish the relationship between marital status and suicidal ideation.

This study reported no associations between age, gender, and suicidal ideation. It has been noted that suicidal ideation increased with the increase of age. ${ }^{20}$ In the present study, the age of participants was younger than the previous study, where $64.5 \%$ of the participants were between 60 and 65 years of age. In the previous study, the mean age of the participants was 71 years old. ${ }^{6}$ In this study, no significant association was reported between gender and suicidal ideation, consistent with the previous studies. ${ }^{6,7}$

The present study reported congruent findings with other studies regarding the significant association between depression and suicidal ideation. It was noted that all cases of suicidal ideation involved those who were categorized as experiencing severe depression. This finding was similar to a previous study. ${ }^{4}$ Given the various populations involved in this research and previous studies, ${ }^{7-9}$ it could be seen that depression remains one of the reasons behind suicidal ideation. As the present study used the screening tool (GDS15) to measure depression, all participants in the severe depression category are not yet diagnosed with depression.

One of the limitations of this study is that it is limited to a small sample size in a single medical outpatient clinic due to time constraints. Furthermore, the research sample consisted of older people who attended to the medical outpatient clinic, but not suicide victims. Thus, the findings could not be generalized to those who have attempted suicide or have committed suicide. Future research would require a bigger sample size and more medical outpatient clinics to provide a clearer understanding of suicidal ideation in older people.

\section{Conclusion}

Overall, $3 \%$ of older people reported suicidal ideation. This study identified that ethnicity, marital status, and depression were significantly correlated with suicidal ideation in older people. This study will serve as a guide for future studies and will concentrate on these factors in any intervention aimed at reducing suicidal ideation among older people in Malaysia.

\section{Conflict of interest}

The authors declare no conflict of interest.

\section{Acknowledgements}

The first author would like to thank all participants in this study.

\section{References}

1. Borges G, Acosta I, Sosa AL. Suicide ideation, dementia and mental disorders among a community sample of older people in Mexico. Int J Geriatr Psychiatry. 2015;30:247-55, http://dx.doi.org/10.1002/gps.4134.

2. Rahimi R, Ali N, Md Noor S, Mahmood MS, Zainun KA. Suicide in the elderly in Malaysia. Malays J Pathol. 2015;37:259-63. PMID: 26712672.

3. Kim SH. Suicidal ideation and suicide attempts in older adults: influences of chronic illness, functional limitations, and pain. Geriatr Nurs. 2016;37:9-12, http://dx.doi.org/10.1016/j.gerinurse.2015.07.006.

4. Lee SY, Atteraya MS. Depression, poverty, and abuse experience in suicide ideation among older Koreans. Int J Aging Hum Dev. 2019;88:46-59, http://dx.doi.org/10.1177/0091415018768256.

5. Li LW, Gee GC, Dong X. Association of self-reported discrimination and suicide ideation in older Chinese Americans. Am J Geriatr Psychiatry. 2018;26:42-51, http://dx.doi.org/10.1016/j.jagp.2017.08.006.

6. Li H, Xu L, Chi I. Factors related to Chinese older adults suicidal thoughts and attempts. Aging Ment Heal. 2016;20:752-61, http://dx.doi.org/10.1080/13607863.2015.1037242.

7. O'Riley AA, Van Orden KA, He H, Richardson TM, Podgorski C, Conwell $Y$. Suicide and death ideation in older adults obtaining aging services. Am J Geriatr Psychiatry. 2014;22:614-22, http://dx.doi.org/10.1016/j.jagp.2012.12.004.

8. Wei J, Zhang J, Deng Y, Sun L, Guo P. Suicidal ideation among the Chinese elderly and its correlates: a comparison between the rural and urban populations. Int J Environ Res Public Health. 2018;15:e422, http://dx.doi.org/10.3390/ijerph15030422.

9. Ro J, Park J, Lee J, Jung $H$. Factors that affect suicidal attempt risk among Korean elderly adults: a path analysis. J Prev Med Public Health. 2015;48:28-37, http://dx.doi.org/10.3961/jpmph.14.030.

10. Lu L, Xu L, Luan X, Sun L, Li J, Qin W, et al. Gender difference in suicidal ideation and related factors among rural elderly: a cross-sectional study in Shandong, China. Ann Gen Psychiatry. 2020;19:2, http://dx.doi.org/10.1186/s12991-019-0256-0.

11. Conejero I, Olié E, Courtet P, Calati R. Suicide in older adults: current perspectives. Clin Interv Aging. 2018;13:691-9, http://dx.doi.org/10.2147/CIA.S130670.

12. McLaren S, Gomez R, Gill P, Chesler J. Marital status and suicidal ideation among Australian older adults: the mediating role of sense of belonging. Int Psychogeriatr. 2015;27:145-54, http://dx.doi.org/10.1017/S1041610214001501.

13. Kim OS, Yoon HS, Park HS, Sok SR. Factors influencing suicide ideation among older Korean adults living alone. J Hosp Palliat Nurs. 2015;17:189-95, http://dx.doi.org/10.1097/NJH.0000000000000143.

14. Jahn DR, Poindexter EK, Cukrowicz KC. Personality disorder traits, risk factors, and suicide ideation among older adults. Int Psychogeriatr. 2015;27:1785-94, http://dx.doi.org/10.1017/S1041610215000174.

15. Ahn J, Kim BJ. The relationships between functional limitation, depression, suicidal ideation, and coping in older Korean immigrants. J Immigr Minor Health. 2015;17:1643-53, http://dx.doi.org/10.1007/s10903-015-0204-2.

16. Sheikh JI, Yesavage JA. Geriatric Depression Scale (GDS): recent evidence and development of a shorter version. Clin Gerontol. 1986;5:165-73, http://dx.doi.org/10.1300/J018v05n01_09.

17. Osman A, Bagge CL, Gutierrez PM, Konick LC, Kopper BA, Barrios FX. The Suicidal Behaviors Questionnaire-Revised (SBQ-R): validation with clinical and nonclinical samples. Assessment. 2001;8:443-54, http://dx.doi.org/10.1177/107319110100800409. 
18. Bahar N, Ismail WSW, Hussain N, Haniff J, Bujang MA, Hamid AM, et al. Suicide among the youth in Malaysia: what do we know? Asia-Pac Psychiatry. 2015;7:223-9, http://dx.doi.org/10.1111/appy.12162.

19. Robustelli BL, Trytko AC, Li A, Whisman MA. Marital discord and suicidal outcomes in a national sample of married individuals. Suicide Life Threat Behav. 2015;45:623-32, http://dx.doi.org/10.1111/sltb.12157.

20. Mezuk B, Rock A, Lohman MC, Choi M. Suicide risk in long-term care facilities: a systematic review. Int J Geriatr Psychiatry. 2014;29:1198-211, http://dx.doi.org/10.1002/gps.4142. 